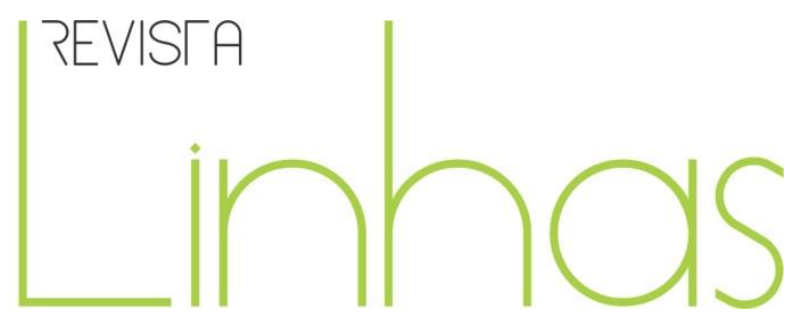

\title{
Fiscalização, orientação e trabalho docente na zona rural: Livros de Termos de Visitas das escolas isoladas de Rio Claro/SP (1970- 1988)
}

\begin{abstract}
Resumo
O presente artigo tem por objetivo analisar algumas das práticas recorrentes nas visitas dos inspetores escolares/supervisores pedagógicos de escolas unidocentes situadas na zona rural do município de Rio Claro, interior do Estado de São Paulo, compreendendo o período entre 1970 e 1988, a fim de recuperar vestígios do trabalho docente na zona rural. O texto analisa os registros resultantes da fiscalização e orientação das autoridades de ensino que anotavam suas observações e recomendações nos Livros de termos de visitas, sendo possível identificar algumas práticas realizadas nas escolas primárias rurais. Após a união, recuperação e seleção das fontes, analisou-se o total de 76 termos de visitas de quatro (4) escolas unidocentes rurais do município de Rio Claro. O estudo aponta como a atuação de inspetores de ensino/supervisores pedagógicos buscava uniformizar a prática docente em escolas primárias, fiscalizando o uso do programa de ensino e orientando as professoras sobre como ministrar uma boa aula. Outros pontos importantes que configuram a profissão docente são abordados no texto, como: constantes mudanças de professoras; faltas; pedidos de remoção; licenças e orientações sobre escrituração, ambiente escolar e distribuição da merenda.
\end{abstract}

Palavras-chave: Termos de Visitas. Supervisão escolar. Educação rural - Práticas de ensino. Análise Documental.

\section{Kamila Cristina Evaristo Leite}

Universidade Estadual Paulista -

UNESP - Marília/SP - Brasil

kamila_evaristoleite@yahoo.com.br

\section{Para citar este artigo:}

LEITE, Kamila Cristina Evaristo. Fiscalização, orientação e trabalho docente na zona rural: Livros de Termos de Visitas das escolas isoladas de Rio Claro/SP (1970-1988). Revista Linhas. Florianópolis, v. 21, n. 47, p. 305327, set./dez. 2020.

DOI: $10.5965 / 1984723821472020305$

http://dx.doi.org/10.5965/1984723821472020305

\footnotetext{
${ }^{1}$ Pesquisa financiada pela CAPEs.
} 


\title{
Surveillance, guidance and teacher work in rural area: Terms of Schools of Rio Claro / SP isolated schools (1970-1988)
}

\begin{abstract}
This article aims to analyze some of the recurring practices in the visits of the school inspectors / pedagogical supervisors of the isolated schools located in the rural area of Rio Claro, interior of the State of São Paulo, covering the period between 1970 and 1988, recovering traces of the teaching work in the countryside. The text analyzes the records resulting from the supervision and guidance of the educational authorities who noted their observations and recommendations in the terms of visit books, and it is possible to identify some practices performed in rural primary schools. After gathering, retrieving and selecting sources, I analyzed the total of 76 terms of visits from 4 isolated schools. The study points out how the performance of teaching inspectors / pedagogical supervisors sought to standardize teaching practice in primary schools, overseeing the use of the teaching program and guiding teachers on how to teach a good class. Other important points that configure the teaching profession are addressed in the text, such as the constant changes of teachers, absences, requests for removal and licenses, guidance on bookkeeping and the school environment and the distribution of meals.
\end{abstract}

Keywords: Terms of Visits. School supervision. Rural education - Teaching practices. Document analysis. 
O presente artigo tem por objetivo analisar algumas das práticas recorrentes nas visitas dos inspetores escolares/supervisores pedagógicos de escolas unidocentes situadas na zona rural do município de Rio Claro, interior do Estado de São Paulo, compreendendo o período entre 1970 e 1988, a fim de recuperar vestígios do trabalho docente na zona rural. O recorte temporal está estritamente ligado à fonte: Livros de Termos de Visitas.

A proposta de análise se refere aos registros resultantes da fiscalização e da orientação das autoridades de ensino que anotavam suas observações e recomendações nos Livros de termos de visitas, sendo possível identificar algumas práticas realizadas nas escolas primárias rurais paulistas. Analisou-se o total de 76 termos de visitas de quatro (4) escolas unidocentes rurais do município de Rio Claro, a partir da atuação de inspetores de ensino/supervisores pedagógicos, que buscava uniformizar a prática docente em escolas primárias localizadas em áreas rurais, fiscalizando o uso do programa de ensino e orientando as professoras sobre como ministrar uma boa aula.

Outros pontos importantes que configuram a profissão docente são abordados no texto, como: constantes mudanças de professoras, faltas, pedidos de remoção, licenças, orientações sobre a escrituração, o ambiente escolar e a distribuição da merenda. E para que se possa atingir o objetivo aqui proposto, é necessário contextualizar as escolas primárias unidocentes (escolas isoladas e as escolas de emergência) e o município de Rio Claro, lócus da pesquisa.

\section{As Escolas Primárias Unidocentes no Estado de São Paulo: as escolas isoladas e as escolas de emergência}

As escolas primárias isoladas exerceram um papel fundamental na expansão do ensino primário paulista na zona rural, ensinando rudimentos dos conteúdos de leitura, escrita e cálculo às crianças. No Estado de São Paulo, Souza (2012) afirma que dos modelos de escolas primárias (Grupos Escolares, Escolas Isoladas, Escolas Reunidas)²

\footnotetext{
${ }^{2}$ Os grupos escolares, as escolas isoladas e as escolas reunidas, principais modelos de escolas primárias paulistas no século XX, existiam tanto na zona urbana quanto na zona rural, porém os grupos escolares
} 
existentes no século XX, dois modelos predominaram: os grupos escolares, implementados principalmente nas zonas urbanas; e as escolas isoladas, nas zonas rurais.

De modo geral, prevaleceram dois modelos de organização pedagógica: as escolas unitárias ou singulares caracterizadas pelo ensino ministrado por um professor a grupos de alunos de diferentes níveis de adiantamento em um mesmo espaço (sala de aula) e as escolas graduadas compreendendo várias salas de aula com vários professores, alunos classificados em classe o mais homogêneo possível pelo nível de adiantamento e a distribuição dos programas em séries. (SOUZA, 2012, p. 35-36)

As escolas isoladas ${ }^{3}$ surgiram das transformações das escolas de primeiras letras existentes no século XIX e foram denominadas escolas preliminares no início do período republicano. Conforme apontado por Souza e Ávila (2015), no ano de 1904 foi legalizado pela primeira vez no Estado de São Paulo o termo 'escola isolada'. O Código de Educação do Estado de São Paulo, de 1933, determinava que as escolas isoladas fossem criadas em diferentes localidades, como fábricas, cidades e vilas, mas foi na zona rural que elas predominaram. Para que pudesse funcionar uma escola isolada nessas localidades, a unidade deveria ter no mínimo 40 crianças em idade escolar e em condições para matrícula, e não poderia haver frequência média inferior a 24 alunos, pois, nesse caso, as escolas seriam transferidas ou fechadas (SÃO PAULO, 1933, p. 324).

Diferente dos grupos escolares, considerados como a modernização do ensino, tendo um aparato físico e pedagógico modernos, as escolas isoladas eram, em sua grande maioria, adaptadas para o ensino, sendo precárias tanto no aspecto físico como no aspecto pedagógico. Cardoso (2013) descreve as escolas isoladas paulistas como um modelo desajustado frente às urbanas, pois comparadas aos grupos escolares, essas escolas eram totalmente contrárias ao ideal de ensino republicano.

Souza (1998) e Silva (2004) observaram algumas características que diferenciavam os grupos escolares das escolas isoladas no Estado de São Paulo. Souza (1998) descreve que os grupos escolares reuniam em um único prédio várias salas de aula, professores, 
alunos divididos em classes homogêneas e um diretor escolar. Silva (2004) indica que as escolas isoladas, entretanto, eram compostas por uma única classe, com alunos heterogêneos, funcionando em prédio adaptado, sob a regência de um único professor. Mesmo as escolas isoladas sendo consideradas precárias, Souza (1998) afirma que a sua necessidade era incontestável:

A necessidade das escolas isoladas era um fato incontestável. Durante as primeiras décadas deste século elas sobreviveram à sombra dos grupos escolares nas cidades, nos bairros e no campo. Apesar de elas serem consideradas tão necessárias, os grupos foram mais beneficiados, e nelas continuou predominando a carência de tudo: materiais escolares, livros, cadernos, salas apropriadas e salários para os professores. (SOUZA, 1998, p.51)

Os estudos de Souza (1998; 2009; 2012); Silva (2004); Ávila (2013); Souza e Ávila (2014; 2015); Moraes (2014); Celeste Filho (2014) abordam alguns problemas e características das escolas primárias rurais paulistas no século XX. Entre eles, destacamse: a precariedade dos prédios escolares, a falta de mobiliário, a falta de material pedagógico, o baixo número de matrículas, a baixa frequência de alunos, o abandono escolar, professores em início de carreira, a ausência e os inúmeros pedidos de remoção e licença dos professores, os baixos salários e a deficiência e irregularidade da inspeção escolar.

Esses autores identificam como características do ensino primário rural comum ${ }^{4}: 0$ curso de menor duração; programas simplificados; o fato de não levar em consideração as diferenças regionais; programa de ensino não adaptado ao meio, com o objetivo de fixar o homem no campo; um único professor; multisseriação; crianças em diferentes níveis de aprendizado; objetivos modestos. Todos esses problemas e características das escolas isoladas demostram a precariedade do ensino na zona rural, seja no Estado de São Paulo ou no Brasil.

Os dados destacados anteriormente fazem referência às escolas isoladas, que até o ano de 1950, eram o modelo de escola primária predominante nas zonas rurais

\footnotetext{
${ }^{4}$ No estado de São Paulo, entre 1930 e 1960, existiram dois modelos de ensino primário rural: o ensino primário rural comum, representado por escolas primárias localizadas na zona rural, e as escolas primárias típicas rurais, que, segundo Moraes (2014), eram compostas pelos grupos escolares rurais, as granjas escolares e as escolas típicas rurais, que seguiam um currículo específico.
} 
paulistas. A partir do ano de 1955, com o Decreto n. 24.400, de 11 de março, surgiu um novo modelo de escola primária no Estado de São Paulo, as Escolas de Emergência (SÃO PAULO, 1955), que segundo Carvalho (1988), foram instaladas em caráter emergencial e tinham como objetivo sanar a demanda de falta de vagas nas escolas primárias paulistas. A emergência se tornou regra, como observou Carvalho (1988), e a Lei n. 3.783, de 05 de fevereiro de 1957, tornou essas escolas oficiais no Estado de São Paulo (SÃO PAULO, 1957).

Com isso, passaram a existir na zona rural paulista dois tipos de escolas primárias comuns, para atender as crianças rurais. Neste texto, será utilizado o termo "Escolas Unidocentes", retirado dos Anuários Estatísticos do Estado de São Paulo, para determinar as escolas isoladas e as escolas de emergência, que funcionavam com apenas um único professor.

As escolas unidocentes foram extintas no Estado de São Paulo no final dos anos de 1980 e início dos anos de 1990, com a reestruturação e o agrupamento das escolas na zona rural, instituídos pelo Decreto n. 29.499, de 5 de janeiro de 1989. Leite (2018) compreendeu que a partir da reestruturação e do agrupamento das escolas unidocentes no Estado de São Paulo, determinou-se o fim das escolas isoladas, permanecendo apenas as escolas de emergência, que, ao longo do processo de fechamento, eram agrupadas e transformadas em escolas nucleadas.

\section{Município de Rio Claro: Lócus da pesquisa}

Rio Claro, cidade do interior do estado de São Paulo, está situada no centro-leste do estado e a cerca de $173 \mathrm{~km}$ da capital, possuindo uma área de 498,422 km². Sua fundação se deu no início do século XIX, em 1827. O município é composto por Rio Claro (sede); os distritos de Ajapi e Assistência; por três bairros rurais - Batovi, Itapé e Ferraz -; e 25 núcleos rurais 5 (NICOLETTI et.al.; 2001, p.40).

\footnotetext{
${ }^{5}$ Segundo o Atlas Escolar - Histórico, Geográfico e Ambiental - do município de Rio Claro, os núcleos rurais são pequenos aglomerados com poucos habitantes, com menos de 50 casas, podendo ter uma capela modesta ou uma escola de $1^{\mathrm{a}}$ a $4^{\mathrm{a}}$ séries, um bar ou venda, onde se pode encontrar um telefone público (NICOLETTI et. al.; 2001, p.40). Os núcleos rurais do município de Rio Claro são: Carangola; Água Branca; Santo Antônio; Santana do Urucaia; Simão; Cachoeirinha; Mata Negra; São José; Mato Bom; Sítio do Itaipé; Boa Vista; São Bento; Batalha; Sobrado; Camacuã; Serra D’Água; Lopes; Cabeça; Horto Florestal; Novo
} 
No período delimitado para este estudo, 1970 a 1988, existia um número considerável de escolas unidocentes no município de Rio Claro. Em 1972, existiam, segundo o Plano Diretor Municipal, 45 escolas de um único professor na zona rural do município; em 1985, 26 escolas unidocentes; em 1987, 25; em 1988, existiam 23 escolas unidocentes; e em 1989, apenas 13 escolas localizadas na zona rural de Rio Claro (SÃO PAULO, 1985, 1987, 1988, 1989).

Dentre essas escolas unidocentes, localizadas na zona rural do município de Rio Claro, as fontes documentais aqui analisadas destacam cinco delas: a $2^{\text {a }}$ Escola Mista de Emergência de Ajapi; a $2^{\text {a }}$ Escola Mista de Ferraz; a Escola Mista da Estação de Itapé; a Escola Mista da Estação de Camaquã; e a $3^{\text {a }}$ Escola Estadual Primeiro Grau (Isolada) da Estação de Batovi. No entanto, poucas são as informações sobre a estrutura e o funcionamento dessas escolas no município, pois muitas documentações, se perderam ao longo do tempo, estão deterioradas ou são de difícil acesso. Apresentam-se aqui algumas informações gerais analisadas no Plano Diretor do município de Rio Claro, que foi publicado no ano de 1972 e diagnosticou a estrutura física das escolas unidocentes do município.

O Plano Diretor (1972) apontou o funcionamento de 45 escolas unidocentes no município de Rio Claro, sendo 34 isoladas e 11 de emergência. Das entidades mantenedoras, 35 escolas eram mantidas pelo Estado e dez, pelo Município. Estavam matriculadas 944 crianças no ensino de $1^{\text {a }}$ grau, sendo 322 alunos matriculados na $1^{\text {a }}$ série; 273, na $2^{\text {a }}$ série; 203 , na $3^{\text {a }}$ série; 146 , na $4^{\text {a }}$ série (RIO CLARO, 1972, p. 29-31.).

Ao analisar a situação dos prédios escolares das escolas unidocentes, a Comissão de Assessoria e Planejamento apresentou no Plano Diretor (1972) a seguinte situação: 17 escolas estavam com prédios em estado precário; 31, com prédios adaptados ao ensino e 16 escolas com instalações sanitárias inadequadas. A Comissão também apontou alguns benefícios, entre eles: 11 escolas com galpão coberto para recreação; 11 com equipamentos necessários para o ensino; 35 escolas com merenda escolar; 5 escolas com assistência dentária; 24 alunos com direito ao transporte escolar (RIO CLARO, 1972, p 2931.)

Cafezal; Quilombo; Campo dos Cochos; Fazenda Velha; Sitinho. 
Nota-se que as escolas unidocentes do município de Rio Claro, em sua grande maioria, eram lugares com espaços adaptados para o ensino das crianças residentes nas zonas rurais do município. Muitos desses problemas foram descritos pelos inspetores/supervisores do ensino na época, como será demonstrado ao longo deste texto.

\section{Apresentação dos Livros de termos de visitas}

Para a análise dos Livros de termos de visitas ${ }^{6}$, fonte que subsidia o presente artigo, seguiu-se o processo de recuperação, reunião, seleção e análise, como descreve Mortatti (1999), para a produção de um texto. A recuperação, reunião e seleção partiram da necessidade de fontes para subsidiar a dissertação de mestrado7.

Os Livros de termos de visitas analisados tinham como propósito registrar algumas das práticas recorrentes observadas e anotadas pela inspeção/supervisão escolar nas escolas isoladas, tendo em vista as orientações dos inspetores de ensino/supervisores pedagógicos. Entre as práticas estavam: fiscalização da escola, dos professores e dos alunos; notificações acerca da frequência dos alunos, da escrituração escolar, dos conteúdos pedagógicos, das aulas-modelo, dos exames finais, da assiduidade dos professores, da organização escolar, das orientações para os alunos e da merenda escolar. Os Livros termos de visitas tinham o caráter de orientação e fiscalização das unidades escolares visitadas.

As visitas às escolas ficavam sob a incumbência dos inspetores de ensino e dos auxiliares de inspeção. Ligeiro (2014) menciona que o Estatuto do Magistério do Estado de São Paulo do ano de $1974^{8}$ alterou a denominação de inspetor de ensino para

\footnotetext{
${ }^{6}$ Os Livros de termos de visitas e as atas dos exames das quatro escolas isoladas foram localizados nos seguintes arquivos: Escola Estadual Cel. Joaquim Salles; Escola Estadual Barão de Piracicaba; Escola Estadual José Fernandes; Escola Municipal Dennizard França Machado, todas elas pertencentes ao município de Rio Claro/SP.

7 Muitas das análises aqui apresentadas são frutos da pesquisa desenvolvida em nível de mestrado em educação, defendida em fevereiro de 2018.

${ }^{8}$ Lei Complementar n. 114, de 13 de novembro de 1974, que institui o Estatuto do Magistério Público de $1^{\mathrm{a}}$ e $2^{\mathrm{a}}$ graus do Estado e dá providências correlatas.
} 
supervisor pedagógico, e em $1978^{9}$ a nomenclatura passou a ser supervisor de ensino, a qual permanece até os dias atuais.

Entre as obrigações dessas autoridades de ensino descritas no Código da Educação do Estado de São Paulo de 1933 estavam: cumprir e fazer cumprir as leis, visitar os estabelecimentos escolares, orientar os diretores e professores, verificar o estado do mobiliário e dos objetos escolares, informar sobre a dedicação e a competência dos diretores e professores, presidir as reuniões ${ }^{10}$ mensais das escolas isoladas, colaborar ativamente no desenvolvimento das instituições e com as missões técnicas e culturais, realizar os exames finais das escolas isoladas, prestar contas ao delegado regional, realizar sindicâncias, aplicar penas e substituir o delegado regional.

Ainda de acordo com o Código da Educação, os auxiliares de inspeção eram colaboradores dos inspetores de ensino e estavam designados a fiscalizar e orientar especificamente as escolas isoladas. Nos Livros de termos de visitas das escolas isoladas do município de Rio Claro/SP foram localizadas visitas dos inspetores de ensino, assim como dos auxiliares de inspeção e dos supervisores pedagógicos.

Sobre as incumbências dos inspetores de ensino e a fiscalização escolar, destacase o art. 315, parágrafo 2, do Código da Educação de 1933, “artigo n. 315. Parágrafo - 2: Visitar os estabelecimentos que forem distribuídos, e inspecionando-os no que concerne à técnica e à eficiência do ensino, à idoneidade e assiduidade dos docentes, e a disciplina e higiene dos alunos." (SÃO PAULO, 1933, p. 335).

Todas as visitas eram registradas em um livro de escrituração próprio, pertencente à Secretaria de Estado dos Negócios da Educação, com o carimbo da Inspetoria Auxiliar de Ensino de Rio Claro. Eram as próprias autoridades de ensino que faziam a abertura do livro e as professoras das escolas isoladas tinham como responsabilidade zelar pelo documento. Como apresentado acima, os inspetores de ensino, os auxiliares de inspeção

\footnotetext{
${ }^{9}$ Lei Complementar n. 201, de 9 de novembro de 1978, que dispõe sobre o Estatuto do Magistério e dá providências correlatas.

10 Leite (2013) realizou uma análise dos Livros de Atas das Reuniões Pedagógicas das Escolas Isoladas de Rio Claro/SP, no período de 1946 a 1966. Nessa pesquisa foram delimitados dois (2) eixos temáticos e nove (9) categorias de análise. Entre os resultados, é possível destacar que as recomendações dos inspetores de ensino constituíam-se na uniformização e normatização do trabalho docente.
} 
e posteriormente os supervisores pedagógicos também realizavam os exames finais das escolas isoladas e/ou escolas unidocentes.

Os Livros de termos de visitas utilizados para este estudo são: Livro de termo de visitas e Atas de exames da $2^{\mathrm{a}}$ Escola Mista de Emergência de Ajapi (1970 a 1976); Livro de

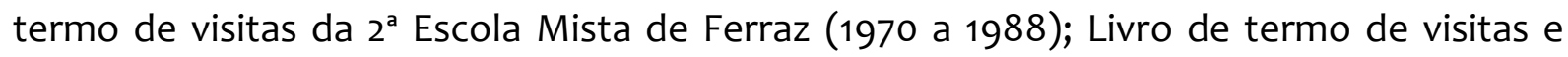
Atas de exames da Escola Mista da Estação de Itapé (1973 a 1981); Livro de termo de visitas e Atas de exames da Escola Mista da Estação de Camaquã e $3^{\text {a }}$ Escola Estadual de Primeiro Grau (Isolada) da Estação de Batovi (1975 a 1980).

No quadro 1 são apresentadas de forma sintética as informações referentes às escolas isoladas e os termos de visitas.

Quadro 1 - Termos de Visitas das Escolas Isoladas do Município de Rio Claro/SP

\begin{tabular}{|c|c|c|c|}
\hline ESCOLA & $\begin{array}{l}\text { PERÍODO } \\
\text { DAS VISITAS }\end{array}$ & $\begin{array}{ll}\text { TOTAL } & \text { DE } \\
\text { TERMOS } & \text { DE } \\
\text { VISITAS } & \end{array}$ & OBSERVAÇÕES \\
\hline $\begin{array}{l}2^{\text {a }} \text { Escola Mista de } \\
\text { Emergência de Ajapi }\end{array}$ & 1970 a 1976 & $\begin{array}{l}22 \text { termos de } \\
\text { visitas }\end{array}$ & $\begin{array}{l}\text { A partir de 1976, a } 2^{\text {a }} \text { Escola } \\
\text { Mista de Emergência de } \\
\text { Ajapi compôs, juntamente } \\
\text { com outras escolas isoladas, } \\
\text { a Escola Agrupada Rural de } \\
\text { Ajapi }\end{array}$ \\
\hline $2^{\mathrm{a}}$ Escola Mista de Ferraz & 1970 a 1988 & $\begin{array}{l}37 \text { termos de } \\
\text { visitas }\end{array}$ & $\begin{array}{l}\text { A partir de } 1980 \text {, a escola } \\
\text { passou a se denominar } \\
\text { Escola Mista de Emergência } \\
\text { de Ferraz }\end{array}$ \\
\hline $\begin{array}{l}\text { Escola Mista da Estação de } \\
\text { Itapé }\end{array}$ & 1973 a 1981 & $\begin{array}{l}11 \text { termos de } \\
\text { visitas }\end{array}$ & $\begin{array}{l}\text { Do ano de } 1979 \text { ao ano de } \\
\text { 1981, há apenas resultados } \\
\text { de exames }\end{array}$ \\
\hline $\begin{array}{c}\text { Escola Mista da Estação de } \\
\text { Camaquã e } 3^{\text {a E.E.P.G }} \\
\text { (Isolada) da Estação de } \\
\text { Batovi }\end{array}$ & 1975 a 1980 & $\begin{array}{l}6 \text { termos de } \\
\text { visitas }\end{array}$ & $\begin{array}{l}\text { O Livro de termo de visitas } \\
\text { foi aberto em } 1975 \text {, mas só } \\
\text { ocorreu visita em } 1977 \text {. } \\
\text { No ano de } 1978 \text {, a escola } \\
\text { passou da Estação de } \\
\text { Camaquã para a Estação de } \\
\text { Batovi }\end{array}$ \\
\hline \multicolumn{2}{|c|}{ Total de termos de visitas } & \multicolumn{2}{|c|}{76 termos de visitas } \\
\hline
\end{tabular}

Fonte: Elaborado pela autora com base nos Livros de Termos de Visitas, 2019 
A documentação é composta por 76 termos de visitas das escolas isoladas, que abrangem o período de 1970 a 1988. No decorrer da periodização desta pesquisa, não há uma mudança considerável na estrutura e no conteúdo dos termos de visitas analisados. A fonte não é volumosa, pois os termos de visitas não ultrapassam uma página escrita. Os inspetores de ensino/supervisores pedagógicos apenas registravam nos termos o ocorrido na visita de forma pontual e sem detalhamento.

Ao quantificar o número de termos de visitas realizados durante o período de 1970 a 1988 em quatro diferentes escolas isoladas do município de Rio Claro/SP, percebe-se que as visitas eram irregulares, pois não ocorriam todos os meses e por vezes nem ao longo de anos. Por exemplo, no livro de termos de visitas da $2^{\mathrm{a}}$ Escola Mista de Ferraz, no período de 1972 a 1974 e nos anos de 1976 e 1985, ocorreram interrupções das vistas dos supervisores pedagógicos nessa escola isolada. Como bem observa Ligeiro (2014), de acordo com a legislação em vigor no Estado de São Paulo, os inspetores de ensino deveriam visitar as escolas ao menos uma vez por mês, fato que, assim como se constata, não ocorria.

Santos e Pereira (1983), ao analisarem a escola rural e o perfil do professor da escola rural do Estado de São Paulo, por meio de um questionário informativo, constataram que as escolas recebiam a visita do Supervisor Pedagógico, porém elas variavam de nenhuma a quatro visitas por semestre letivo. As autoras também apontam outras informações relevantes sobre as visitas às escolas isoladas: "as mesmas tiveram objetivo: orientar o professor, verificar o aproveitamento e assiduidade dos alunos e o andamento da escola como um todo." (SANTOS; PEREIRA, 1983, p. 106-107).

Em relação à estrutura dos termos de visitas, não houve verificação de que se alterava muito, apenas o conteúdo ou a orientação do inspetor de ensino/supervisor pedagógico variavam ao longo do tempo.

Ao iniciar o termo de visita, o inspetor de ensino/supervisor pedagógico colocava data, quem estava regendo a escola no dia da visita, a frequência dos alunos, observações sobre a professora, as atividades realizadas (verificar cadernos de alunos e escrituração escolar, assistir aula, dar aula, orientar a professora, conversar com os alunos, observar a disciplina escolar e a merenda), por fim, colocava local e data e assinava o documento.

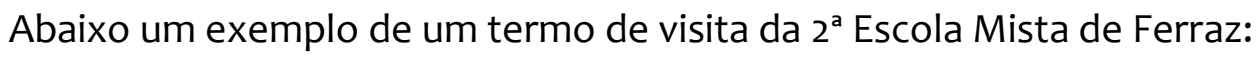


Estive hoje, a serviço do cargo, nesta escola ( $2^{\mathrm{a}}$ Isolada de Ferraz, município de Rio (laro), encontrando-a em regular funcionamento, sob a regência da Sra. Profa. M. E. T. C., que substitui M. A. S., por sua vez licenciada. A escola ressente-se da falta de mobiliário adequado para os alunos (carteiras), de vez que dispõe apenas de mesinhas mais apropriadas para a classe de pré-escola municipal, que funciona na mesma sala, noutro período. Reiterados pedidos já foram feitos, em vão. A sala, por outro lado, necessita de uma reforma (pisos, pintura, etc.). Dei e assisti aulas; fiz algumas sugestões a respeito do uso de livros de textos e/ou auxiliares para língua portuguesa, matemática, estudos sociais e ciências. Constatei a matrícula de 32 alunos ( 18 da $1^{\mathrm{a}}$ série e 14 da $3^{\mathrm{a}}$ série), dos quais dois ausentes. Levo ótima impressão do trabalho da Sra. Profa. (TERMO DE VISITA DA $2^{\circ}$ ESCOLA MISTA DE FERRAZ, 1988, [p.25-26]) ${ }^{11}$

Os Livros termos de visitas e Atas de exames eram documentos produzidos na própria unidade escolar pelo inspetor, auxiliar de ensino ou pelo supervisor pedagógico. Com o objetivo de anotar as ocorrências observadas no dia da visita, "os inspetores escolares, em suas visitas às unidades escolares, registravam suas observações e recomendações de próprio punho em um livro destinado especificamente a esse fim, chamado de livro de Termos de Visitas" (LIGEIRO, 2014, p.48).

Os inspetores de ensino, os auxiliares de inspeção e, posterior ao ano de 1974, o supervisor pedagógico (atualmente os supervisores de ensino) são profissionais que tinham, e ainda têm, entre as suas atribuições, a fiscalização das escolas urbanas e rurais existentes no município ou estado. Ligeiro (2014) aponta que a fiscalização e as orientações realizadas por esses agentes da administração escolar ficavam registradas nos termos de visitas e deveriam ser cumpridas pelos diretores e professores das escolas visitadas.

Os professores das escolas isoladas rurais eram responsáveis pela escrituração das escolas que estavam sob sua incumbência. Nas reuniões pedagógicas ${ }^{12}$, as recomendações eram frequentes para que os professores preenchessem a documentação cuidadosamente e preservassem os documentos escolares.

\footnotetext{
${ }^{11}$ Visita realizada em 24/03/1982.

${ }^{12}$ As reuniões pedagógicas eram uma prática recorrente nas escolas primárias, segundo Souza e Leite (2016). Com base no Código de Educação do Estado de São Paulo de 1933, as reuniões apresentavam a seguinte finalidade: "imprimir maior qualidade, eficiência, racionalidade e padronização no ensino primário".
} 
Leite (2013a), ao analisar atas das reuniões pedagógicas das professoras das escolas isoladas do município de Rio Claro/SP, demonstra que é perceptível nessas leituras a exigência por parte das autoridades do ensino para o correto preenchimento e o zeloso cuidado pelos livros de escrituração escolar, que compunham alguns documentos, tais como: livro de matrícula, livro de chamada, resumos mensais e estatística e os termos de visitas.

Fazendo alusão à orientação sobre os cuidados, o correto preenchimento e a preservação da escrituração escolar, na visita de maio de 1976 à Escola Mista da Estação de Itapé, o inspetor de ensino registrou no livro de termos de visita a seguinte observação: "transmiti a Sra. Profa. instruções sobre escrituração escolar (prontuário dos alunos, matrícula e eliminação, critério para conversão das notas em menções literárias, etc.)" (TERMO DE VISITA DA ESCOLA MISTA DA ESTAÇÃO DE ITAPÉ, 1981, [p.11])13.

Nota-se que as prescrições para o zelo com a escrituração escolar estavam entre os deveres que as professoras primárias rurais deveriam cumprir em sua prática docente. Assim como limpar e organizar a escola, preparar e servir a merenda, quando não houvesse a merendeira, entre outras tarefas não delimitadas como pedagógicas.

Na próxima seção, serão apresentados alguns elementos da profissão docente na zona rural, destacando as orientações pedagógicas, as aulas-modelo e o trabalho docente.

\section{Profissão docente na zona rural: orientações pedagógicas, aulas-modelo e trabalho docente}

O exame dos termos de visitas possibilitou compreender as práticas recorrentes nas escolas unidocentes. Entre as já citadas, destacam-se apenas três: as orientações pedagógicas, as aulas-modelo e o trabalho docente, visto que estas práticas auxiliam na compreensão da profissão docente na zona rural.

Entre as orientações pedagógicas mais recorrentes nos termos de visitas pode-se listar: leitura, escrita e cálculo. Conforme aponta Souza (2009), nas escolas primárias paulistas os conteúdos pedagógicos se limitavam ao bom ensinamento da leitura, da

\footnotetext{
13 Visita realizada em 26/05/1976.
} 
escrita e do cálculo, deixando conteúdos de história, geografia e ciências em segundo plano, assim como trabalhos manuais, que eram pouco citados.

Os inspetores também orientavam sobre planejamento escolar, utilização do programa de ensino, movimentação dos trabalhos escolares e meios para melhorar o aproveitamento dos alunos fracos. Abaixo relaciona-se a descrição do inspetor de ensino sobre uma conversa que teve com a professora da Escola Mista da Estação de Itapé:

Estive hoje nesta escola no exercício das funções de meu cargo, encontrando-a em regular funcionamento, sob a regência da Sra. Profa. M. de A. B., com quem conversei demoradamente sôbre técnicas e recursos didáticos, oferecendo-lhe, a propósito, algumas sugestões. (TERMO DE VISTA DA ESCOLA MISTA DA ESTAÇÃO DE ITAPÉ, 1981, $[\mathrm{p.9}])^{14}$

Ao registrar as recomendações sobre os conteúdos pedagógicos nos termos de visitas, os inspetores de ensino/supervisor pedagógico orientavam e fiscalizavam o uso do programa de ensino. Como a escrituração escolar, os conteúdos pedagógicos também eram orientação recorrente nas reuniões pedagógicas. Cabe ressaltar que essas reuniões apresentavam muitas orientações de diferentes assuntos e as visitas do inspetor de ensino/supervisor pedagógico também eram uma forma de orientar e fiscalizar o cumprimento das recomendações passadas nelas.

Conversei com a Sra. Profa. sôbre as diversas áreas do programa de ensino, esclarecendo assuntos e deixando orientações para as aulas de linguagem e de matemática. (TERMO DE VISITA DA $2^{\mathrm{a}}$ ESCOLA MISTA DE EMERÊNCIA DE AJAPI, 1976, [p.4]) $)^{15}$

Tratei, com a Sra. Profa. da movimentação dos seguintes assuntos: a) combate à formiga; b) Folclore; c) semana da avicultura; d) desenvolvimento do programa de ensino, tendo deixado sugestões e orientações sôbre as diversas áreas de estudo (TERMO DE VISITA DA ESCOLA MISTA DE EMERGÊNCIA DE AJAPI, 1976, [p.4-5]) $)^{16}$

\footnotetext{
14 Visita realizada em 04/05/1975.

15 Visita realizada em 15/05/1970.

${ }^{16}$ Visita realizada em 18/08/1970.
} 
Encontrei a classe entregue a atividade de jardinagem ${ }^{17}$, pelo que constatei a louvável iniciativa da professora no sentido de despertar, nos alunos, o amor às plantas e o respeito à natureza. (TERMO DE VISITA DA ESCOLA MISTA DA ESTAÇÃO DE CAMACUÃ, 1980, [p.3]) $)^{18}$

Orientei a Sra. Profa. no tocante a adoção do material didático para classe, bem como quanto ao desenvolvimento das aulas, de modo geral. (TERMO DE VISITA DA ESCOLA MISTA DA ESTAÇÃO DE CAMACUÃ, FEVEREIRO, 1980, [p.5]) $)^{19}$

A profa. está usando a Cartilha ${ }^{20}$ "Aprender a viver". Um aluno está na lição da "Vaca", outro, na da "Roda" e 19 na da "Gata". Verifiquei ditado em que se englobou todas as lições, com bom resultado. Em matemática está seguindo as orientações do monitor da D.E., estando na "atividade 20", iniciando adição" (TERMO DE VISITA DA $2^{\text {a }}$ ESCOLA MISTA DE FERRAZ, 1988, [p.32-33] $\left.]^{21}\right)$

Verifiquei, no dia, a avaliação de Língua Portuguesa com interpretação de texto, Ditato, digo, ditado, bilhete, exercício de gramática. Em matemática já deu equivalência e simplificação de fração e problemas com as 4 operações e divisão por 2 algarismos ${ }^{22}$. (TERMO DE VISITA DA $2^{\mathrm{a}}$ ESCOLA MISTA DE FERRAZ, 1988, [p.33] $)^{23}$

Os termos de visitas como instrumento de fiscalização apresentam registros importantes para refletir sobre o trabalho docente. Observa-se neles a referência de que as autoridades de ensino deram e assistiram as aulas, porém poucos são os registros detalhados sobre o seu conteúdo pedagógico. Nesse sentido, é possível afirmar que as aulas ministradas pelas autoridades de ensino consistiam em meios de normatizar e uniformizar o trabalho docente.

Os inspetores de ensino não ficavam apenas nos registros de orientações para as professoras. Nos termos de visitas há menção de que os inspetores de ensino ministravam aulas para os alunos e as professoras assistiam as aulas e aprendiam como

\footnotetext{
${ }_{17}$ Atividades de jardinagem e a horta escolar eram recomendados pelos inspetores de ensino nas reuniões pedagógicas (LEITE, 2013a).

${ }^{18}$ Visita realizada em 13/05/1977.

${ }^{19}$ Visita realizada em 05/02/1978.

${ }^{20}$ Nas reuniões pedagógicas também se abordavam assuntos referentes ao material didático. No início de cada ano letivo, havia a ata da escolha dos livros e das cartilhas que seriam adotados pelas professoras das escolas isoladas. (LEITE, 2013b).

${ }^{21}$ Visita realizada em 18/06/1986.

22 A verificação das avaliações de língua portuguesa e matemática a que o supervisor pedagógico faz referência corresponde às dos alunos do $4^{\circ}$ ano primário.

${ }^{23}$ Visita realizada em 18/06/1986.
} 
ministrar corretamente o conteúdo pedagógico. A esse respeito, Souza (2009) afirma que as "aulas modelo eram ministradas pelos inspetores escolares visando à orientação técnica do ensino" (SOUZA, 2009, p.210). Isso é possível observar em um dos termos de visitas da Escola Mista de Emergência de Ajapi: “Dei uma aula sôbre frações ordinárias até $\frac{\mathbf{1}}{\mathbf{9}}$ e com aplicação em problemas. Os alunos reagiram favoravelmente." (TERMO DE

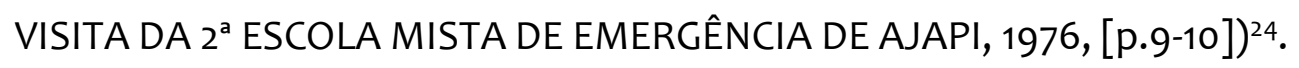

As autoridades de ensino, ao visitarem as escolas, fiscalizavam o andamento do ensino, da disciplina e o cumprimento dos deveres das professoras ${ }^{25}$. Pode-se citar como deveres dessas docentes o cumprimento do programa de ensino, manter a disciplina na sala de aula e cumprir a sua jornada de trabalho. Porém, o trabalho docente na zona rural não se limitava apenas a cumprir essas exigências, como também zelar e manter em dia a escrituração escolar, manter a organização e a limpeza da sala de aula e distribuir a merenda escolar, quando não houvesse merendeira.

Os inspetores de ensino/supervisores pedagógicos também teciam elogios às professoras, assim como registravam se elas se encontravam em licença, se haviam sido removidas para outra unidade escolar, quem era a professora substituta e recebiam reclamações dos familiares sobre o funcionamento das escolas. A seguir, apresentam-se vários registros em que os inspetores de ensino/supervisores pedagógicos tecem comentários sobre o trabalho das professoras:

Promovi uma reunião com os cinco professores, focalizando assuntos relacionados diretamente com o planejamento escolar, escrituração, movimentação das aulas, atividades docentes, etc. (TERMO DE VISITA DA $2^{\mathrm{a}}$ ESCOLA MISTA DE EMERGÊNCIA DE AJAPI, 1976, [p.2] $)^{26}$

O ambiente de trabalho aqui é muito bom. A Sra. Profa. é dedicada aos seus alunos e ao seu trabalho docente. (TERMO DE VISITA DA $2^{\mathrm{a}}$ ESCOLA MISTA DE EMERGÊNCIA DE AJAPI, 1976, [p.3] $)^{27}$

\footnotetext{
${ }^{24}$ Visita realizada em 17/08/1971.

25 Designar-se-á sempre professoras por contar em todos os termos de visitas apenas mulheres nessa função.

${ }^{26}$ Visita realizada em 24/02/1970.

${ }^{27}$ Visita realizada em 21/03/1970.
} 
Tive a melhor das impressões da classe e da escola, que refletem, sem dúvida, a excelente atuação da Sra. Profa., a quem transmito meus elogiosos cumprimentos. (TERMO DE VISITA DA $2^{\text {a }}$ ESCOLA MISTA DE FERRAZ, 1988, $[\mathrm{p} .3])^{28}$

A sala de aula e o prédio escolar estão bem limpos, havendo bom aspecto e muita ordem. (TERMO DE VISITA DA $2^{\text {a }}$ ESCOLA MISTA DE EMERGÊNCIA DE AJAPI, 1976, [p.14] $)^{29}$

Estive hoje nesta escola, encontrando-a em regular funcionamento, sob a regência da Sra. Profa. Edite Maria Brigatto Pinhati, que está aguardando para breves dias sua remoção para outra escola. (TERMO DE VISITA DA ESCOLA MISTA DA ESTAÇÃO DE ITAPÉ, 1981, [p.5] $)^{30}$

Assisti ao funcionamento da merenda escolar, constituída, hoje de leite, para cujo preparo a Sra. Profa. conta com a colaboração de uma vizinha, prestimosa mãe de aluno. (TERMO DE VISITA DA ESCOLA MISTA DA ESTAÇÃO DE ITAPÉ, 1981, [p.11-12]) $)^{31}$

No exercício das funções de meu cargo, visitei hoje a $E E 1^{\circ} \mathrm{G}$ (Isolada) da Estação de Itapé, encontrando-a em regular funcionamento, sob a regência da Sra. Profa. M. B. M. de C., que vem substituindo a professora efetiva, $D^{a} M$. de $F$. de A. B., em gozo de licença especial (gestante). (TERMO DE VISITA DA ESCOLA MISTA DA ESTAÇÃO DE ITAPÉ, 1981, $[\mathrm{p} .11])^{32}$

No dia de hoje, véspera do "Dia do Professor", a professora recebeu significativa homenagem, por parte dos alunos, da qual participei prazerosamente. (TERMO DE VISITA DA $2^{\mathrm{a}}$ ESCOLA MISTA DE FERRAZ, 1988, [p.9] $)^{33}$

Digno de registro é o fato da Sra. Professora preocupar-se também com o ensino de trabalhos manuais (bordados, dobraduras, amarração de franjas em toalhas, etc). Parabéns. (TERMO DE VISITA DA $2^{\circ}$ ESCOLA MISTA DE FERRAZ, 1988, [p.14] $)^{34}$

Solicitei informações da professôra sôbre a denúncia apresentada pelo Sr. J. V. S., pai de aluno, de que as duas professoras do período da manhã vêm dispensando os alunos às 9 horas. Informou-me, ela, que realmente o problema existiu durante 5 ou 6 dias, por falta de condução para retornar à cidade. Levei ao conhecimento da professôra que o professor que reside fora do local de trabalho não pode alegar motivo de

\footnotetext{
${ }^{28}$ Visita realizada em 27/11/1971.

29 Visita realizada em 07/03/1972.

30 Visita realizada em 01/03/1974.

${ }^{31}$ Visita realizada em 26/05/1976.

32 Visita realizada em 26/05/1976.

33 Visita realizada em 14/10/1977.

34 Visita realizada em 22/08/1978.
} 
condução, para dispensar os alunos. Solicitei um plano de trabalho para a reposição das horas que deixaram de ser cumpridas. Solicitei, ainda, que a professora mantenha contato com o pai denunciante e esclareça os fatos. (TERMO DE VISITA DA EEPG (ISOLADA) DA ESTAÇÃO DE BATOVÍ, 1980, [p.6] $)^{35}$

A professora D. P. R., da $2^{\mathrm{a}}$ EEPG da Estação de Batoví, está ausente desde o dia de ontem - 07/03/79. A $3^{\text {a }}$ escola, sob regência da Profa. C., está funcionando normalmente. (TERMO DE VISITA DA EEPG (ISOLADA) DA ESTAÇÃO DE BATOVÍ, 1980, [p.6-7] $)^{36}$

Visita de rotina, antes do encerramento das aulas do período que precede as férias de inverno. Os trabalhos transcorrem normalmente, sendo de se apreciar a rigorosa observância do horário da professora. (TERMO DE VISITA DA 2 ${ }^{\mathrm{a}}$ ESCOLA MISTA DE FERRAZ, 1988, [p.23-24]) ${ }^{37}$

Queremos parabenizar a professora pelo trabalho que vem desenvolvendo, sendo muito elogiada pelos pais e também pela nossa observação, através dos cadernos dos alunos. (TERMO DE VISITA DA $2^{\circ}$ ESCOLA MISTA DE FERRAZ, 1988, [p.37] $)^{38}$

Os comentários aqui apresentados demonstram vários elementos da profissão docente, como: a falta de professores, denúncias por parte dos pais dos alunos, o cumprimento do horário escolar e do currículo, elementos esses que apresentam vestígios da cultura escolar das escolas unidocentes no Estado de São Paulo e como era desenvolvida a prática docente nesses estabelecimentos.

Outra informação relevante extraída dos termos de visitas sobre a profissão docente é a constante mudança de professoras nas escolas isoladas. Celeste Filho (2014) e Oriani (2015) apontam que os constantes pedidos de licença ou remoção das professoras das escolas isoladas rurais se deviam às precárias condições de trabalho, moradia e transporte que essas profissionais enfrentavam na docência na zona rural.

No Livro de termos de visitas da Escola Mista da Estação de Itapé foi contabilizado um total de oito professoras durante o período de 1973 a 1981, sendo que nenhuma delas permaneceu mais do que dois anos consecutivos na escola. Em contrapartida, também foi

\footnotetext{
35 Visita realizada em 06/03/1979.

${ }^{36}$ Visita realizada em 08/03/1979.

37 Visita realizada em 26/06/1981.

${ }^{38}$ Visita realizada em 25/08/1987.
} 
contabilizado que a professora N. M., da $2^{\text {a }}$ Escola Mista de Emergência de Ajapi, permaneceu durante sete anos na mesma escola.

Pode-se assim observar que ocorria uma grande rotatividade de professoras nas escolas unidocentes, como também pedidos de remoção e licenças, mas há também casos em que as professoras permaneciam um longo tempo nessas escolas.

\section{Considerações}

As visitas dos inspetores de ensino nas escolas primárias rurais (escolas unidocentes) sempre tiveram o intuito da fiscalização e do reforço das orientações mencionadas nas reuniões pedagógicas. Ao analisar os 76 termos de visitas de quatro diferentes escolas unidocentes rurais, foi possível perceber que a fiscalização não era efetiva, pois não ocorria regularmente. Porém, quando as visitas aconteciam, os inspetores de ensino observavam e anotavam tudo o que consideravam importante mencionar sobre a escola visitada.

Entre as observações e as anotações dessas autoridades do ensino, pode-se destacar: a frequência escolar, observações sobre o trabalho das professoras, atividades realizadas pelos inspetores de ensino/supervisores pedagógicos no dia da visita (verificar cadernos de alunos e escrituração escolar, assistir e dar aula, orientar a professora, conversar com os alunos, observar a disciplina escolar e a distribuição da merenda) e as reclamações de pais de alunos.

Como fonte de pesquisa, os termos de visitas auxiliam na construção da representação das escolas unidocentes nas zonas rurais paulista e na análise da profissão docente de professoras primárias que exerceram a docência na zona rural. Ao abordar temas sobre as escolas e as professoras, mesmo que sucintos, podem-se construir vestígios do que foram as escolas primárias rurais e a profissão docente na zona rural no século XX. 


\section{Referências}

SÃO PAULO (Estado). Anuário estatístico do estado de São Paulo 1989: CIE. São Paulo, SP: Governo do Estado, 1990.Anual.

SÃO PAULO (Estado). Anuário estatístico do estado de São Paulo 1988: CIE. São Paulo, SP: Governo do Estado, 1989. Anual.

SÃO PAULO (Estado). Anuário estatístico do estado de São Paulo 1987: CIE. São Paulo, SP: Governo do Estado, 1988. Anual.

SÃO PAULO (Estado). Anuário estatístico de educação do estado de São Paulo 1985: CIE. São Paulo, SP: Governo do Estado, 1984. Anual.

ÁVILA, Virgínia Pereira da Silva. História do ensino primário rural em São Paulo e Santa Catarina (1921 - 1952) - uma abordagem comparada. 2013. 241f. Tese (Doutorado em Educação Escolar) - Faculdade de Ciências e Letras, Universidade Estadual Paulista, Araraquara, 2013.

CARDOSO, Maria Angélica. Escolas isoladas paulistas: um modelo desajustado? Revista Linhas, Florianópolis, v. 14, n. 27, p. 201-233, jul./dez. 2013. Disponível em: http://www.revistas.udesc.br/index.php/linhas/article/viewFile/1984723814272013201/2816 Acesso em: 17. jan. 2017.

CARVALHO, Célia Pezzolo de. O difícil acesso à escola pública de São Paulo, 1945 - 1964. 1988. 219f. Tese (Doutorado em Educação) - Faculdade de Educação, Universidade Estadual de Campinas, Campinas, 1988.

CELESTE FILHO, Marcioniro. O espírito de horror à vida educativa nos campos: a educação rural paulista nas décadas de 1930 e 1940. Hist.Educ.[Online], Porto Alegre, v. 18, n. 43, p. 49-70. maio/ago/2014. Disponível em:

http://seer.ufrgs.br/index.php/asphe/article/view/39618/pdf_30. Acesso em: 19. jan. 2017.

LEITE, Kamila Cristina Evaristo Leite. Memórias de professoras de escolas rurais (Rio Claro - SP, 1950 a 1992. 2018. 174f. Dissertação (Mestrado em Educação) - Faculdade de Filosofia e Ciências, Universidade Estadual Paulista, Marília, 2018.

LEITE, Kamila Cristina Evaristo. As práticas educativas nas escolas primárias isoladas paulistas (1940 - 1960). 2013. 84 f. Relatório de Pesquisa (Iniciação Científica) - Programa PIBIC/UNESP/CNPq - apresentado a Pró-reitora de Pesquisa da UNESP, Araraquara, 2013a.

LEITE, Kamila Cristina Evaristo. As práticas educativas no ensino primário: um estudo histórico sobre as Escolas Isoladas de Rio Claro (1940 - 1960). Revista do Arquivo, Rio Claro, n. 11, p. 50-53, junho de 2013b. 
LIGEIRO, Dulcinéia Conceição. A inspeção escolar no estão de São Paulo: análise de termos de visitas (1922-1966). 2014. 117 f. Dissertação (Mestrado em Educação) - Centro Universitário Moura Lacerda, Ribeirão Preto, 2014.

MORAES, Agnes lara Domingos. Ensino primário tipicamente rural no Estado de São Paulo: um estudo sobre as Granjas Escolares, os Grupos Escolares Rurais e as Escolas Típicas Rurais (1933-1968). 2014. 183f. Dissertação (Mestrado em Educação) - Faculdade de Filosofia e Ciências, Universidade Estadual Paulista, Marília, 2014.

MORTATTI, Maria do Rosário Longo. Notas sobre linguagem, texto e pesquisa histórica em educação. História da Educação, Pelotas; ASPHE/FaE/UFPel, v. 6, p. 69-77, out. 1999.

NICOLETTI, Fabiana. et.al.; Atlas municipal escolar: geográfico, histórico, ambiental. FAPESP. Prefeitura Municipal de Rio Claro: UNESP - Campus de Rio Claro, 2001.

RIO CLARO. Inspetoria Auxiliar de Ensino de Rio Claro. Secretaria de Estado dos Negócios da Educação. Livro de Têrmos de Visitas e de termos de Exames: Escola Mista da Estação de Camacuã. Rio Claro: [A Inspetoria], 1975.

RIO CLARO. Comissão de Assessoria e Planejamento. Plano diretor integrado do município de Rio Claro Estado de São Paulo. Rio Claro: [Prefeitura Municipal], 1972.

RIO CLARO. Inspetoria Auxiliar de Ensino de Rio Claro. Secretaria de Estado dos Negócios da Educação. Livro de Têrmos de Visitas e de termos de Exames: Escola Mista da Estação de Itapé. Rio Claro: [A Inspetoria], 1973.

RIO CLARO. Inspetoria Auxiliar de Ensino de Rio Claro. Secretaria de Estado dos Negócios

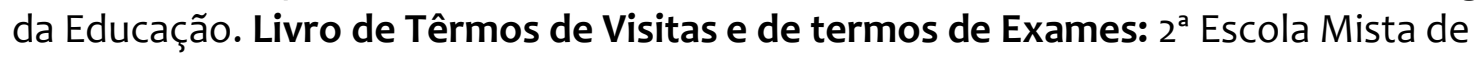
Ferraz. Rio Claro: [A Inspetoria], 1970.

RIO CLARO. Inspetoria Auxiliar de Ensino de Rio Claro. Secretaria de Estado dos Negócios da Educação. Livro de Têrmos de Visitas e de termos de Exames: $2^{\text {a }}$ Escola Mista de Emergência de Ajapi. Rio Claro: [A Inspetoria], 1966.

SANTOS, Maria Aparecida dos; PEREIRA, Maria Candida Sandoval C. O professor e o ensino na escola rural em São Paulo. In: Escolarização no meio rural/; condições sócioeconômicas e pedagógicas do seu desenvolvimento. São Paulo, SE/CENP, 1983.

SÃO PAULO (Estado). Decreto n. 29.499, de 5 de janeiro de 1989. Dispõe sobre a reestruturação e agrupamento das escolas da zona rural. São Paulo: Assembléia Legislativa,1989. Disponível em:

http://www.al.sp.gov.br/repositorio/legislacao/decreto/1989/decreto-2949905.01.1989.html Acesso em: 01. abr.17.

SÃO PAULO (Estado). Lei n. 3.783, de 05 de fevereiro de 1957. Dispõe sôbre a criação de escolas de emergência, e das outras providências. São Paulo: Assembléia Legislativa, 
1957. Disponível em: http://www.al.sp.gov.br/repositório/legislação/lei/1957/lei-378305.02.1957.html Acesso em: 20 maio 2017.

SÃO PAULO (Estado). Decreto n. 24.400, de 11 de março de 1955. Dispõe sôbre a instalação de classes de emergência, de ensino primário. São Paulo: Assembléia Legislativa, 1955. Disponível em:

http://www.al.sp.gov.br/repositorio/legislacao/decreto/1955/decreto-2440011.03.1955.html Acesso em: 20. maio. 2017.

SÃo PAULO (Estado). Código da Educação do Estado de São Paulo. Decreto n. 5.884, de 21 de abril de 1933. São Paulo: Imprensa Oficial, 1933.

SILVA, Denise Guilherme da. Ilhas de saber: prescrições e práticas das escolas isoladas do estado de São Paulo (1933-1943). 2004. 127f. Dissertação (Mestrado em Educação) Pontifícia Universidade Católica de São Paulo, São Paulo, 2004.

SOUZA, Rosa Fatima de; LEITE, Kamila Cristina Evaristo Leite. Prescrições para a prática docente: estratégias de uniformização do ensino primário nas escolas isoladas paulistas (Rio Claro, 1946-1966). In: LIMA, Sandra Cristina Fagundes de; MUSIAL, Gilvanice Barbosa da Silva. (orgs.). Histórias e memórias da escolarização das populações rurais: sujeitos, instituições, práticas, fontes e conflitos. Jundiaí: Paco Editorial, 2016. p.321-348.

SOUZA, Rosa Fátima de; ÁVILA, Virgínia Pereira da Silva de. Para uma genealogia da escola primária rural: entre o espaço e a configuração pedagógica (São Paulo, 1889-1947). Roteiro, Joaçaba, v.40, n.2, p.293-310, jul./dez. 2015. Disponível em http://editora.unoesc.edu.br/index.php/roteiro/article/view/7462/4928. Acesso em: 14 nov. 2016.

SOUZA, Rosa Fátima de; ÁVILA, Virgínia Pereira da Silva de. As disputas em torno do ensino primário rural (São Paulo, 1931-1947). Hist. Educ. [Online], Porto Alegre, v.18, n.43, p.13-32, maio/ago. 2014. Disponível em:

http://seer.ufrgs.br/index.php/asphe/article/view/39553/pdf_21 Acesso em: 14 nov. 2016.

SOUZA, Rosa Fatima de. As escolas públicas paulistas na primeira república: subsídios para a história comparada da escola primária no Brasil. In: Araújo, José Carlos Souza; Souza, Rosa Fatima de; Pinto, Rubia-Mar. Nunes. Escola primária na primeira república (1889-1930): subsídios para uma história comparada. Araraquara: Junqueira \& Marin, 2012. p. 23-77.

SOUZA, Rosa Fatima de. Alicerces da Pátria: história da escola primária no estado de São Paulo (1890-1976). Campinas: Mercado de Letras, 2009.

SOUZA, Rosa Fatima de. Templos de civilização: a implementação da escola primária graduada no Estado de São Paulo (1890-1910). São Paulo: Fundação Editora da UNESP, 1998. 
Recebido em: 28/10/2019 Aprovado em: 13/10/2020

Universidade do Estado de Santa Catarina - UDESC Programa de Pós-Graduação em Educação - PPGE Revista Linhas Volume 21 - Número 47 - Ano 2020 revistalinhas@gmail.com 